\title{
Improvement of Power Quality with PI and Fuzzy controlled DSTATCOM
}

\author{
P. Akhil Raj Koti ${ }^{1}$, M. Nagaraju ${ }^{2}$ \\ M. Tech Dept of EEE, Vignan's Lara Institute of Technology and Science, Guntur, India ${ }^{1}$ \\ Assistant Professor, Dept of EEE, Vignan's Lara institute of Technology and Science, Guntur, India ${ }^{2}$
}

\begin{abstract}
In the recent years rapid development of power electronics and their usage in domestic applications is the major cause for low power quality in distribution system .This can also be due to insufficient VAR support and load unbalance. Power quality problems are mainly classified into three categories. They are voltage fluctuations (sag, swell $\&$ flicker), harmonics, low power factor. In all the power quality problems voltage sag and swell are frequently occurs and affects consumers largely. This power quality problem is mitigated by different custom FACTs devices like SVC, TCR and DSTATCOM etc. In all DSTATCOM gives better performance because of faster response, large operating region. In this project the performance of DSTATCOM is verified to mitigate voltage sag, swell, sudden loading and source harmonics in distribution system. It is also verified with soft computing techniques like fuzzy. The results of soft computing techniques are compared with PI control. The distribution system, DSTATCOM and controllers are simulated in MATLAB/SIMULINK.
\end{abstract}

Key Words: Distribution Static Compensator (DSTATCOM), Distribution Power System, Fuzzy Logic Control, Proportional and Integral (PI) Control.

\section{INTRODUCTION}

The quality of available supply power has a direct economic impact on industrial and domestic sectors which affects the growth of any nation [1]. This issue is more serious in electronic based systems. The level of harmonics and reactive power demand are popular parameters that specify the degree of distortion and reactive power demand at a particular bus of the utility [2]. The harmonic resonance is one of the most common problems reported in low- and medium-level distribution systems. It is due to capacitors which are used for power factor correction (PFC) and source impedance [3]. Power converter based custom power devices (CPDs) are useful for the reduction of power quality problems such as PFC, harmonic compensation, voltage sag/swell compensation, resonance due to distortion, and voltage flicker reduction within specified international standards [4]-[6]. These CPDs include the distribution static compensator (DSTATCOM), dynamic voltage restorer, and unified power quality conditioner in different configurations [7]-[9]. Some of their new topologies are also reported in the literature such as the indirect matrix converter based active compensator where the dc-link capacitor can be removed [10]. Other new configurations are based on stacked multi cell converters where the main features are on the increase in the number of output voltage levels, without transformer operation and natural self-balancing of flying capacitor voltage, etc. The performance of any custom power device depends very much upon the control algorithm used for the reference current estimation and gating pulse generation scheme [11]. Some of the classical control algorithms are the Fryze power theory, Budeanu theory, p-q theory and SRF theory, Lyapunov-function-based control and nonlinear control technique etc. Many non model and training-based alternative control algorithms are reported in the literature with application of soft computing technique such as neural network, fuzzy logic and adaptive Neuro-fuzzy, etc [12]. Adaptive learning, self organization, real-time operation, and fault tolerance through redundant information are major advantages of these algorithms [13$15]$.

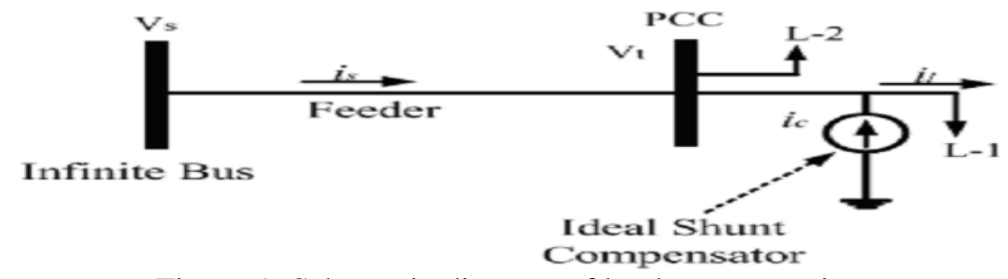

Figure.1. Schematic diagram of load compensation

In order to regulate the dc-link capacitor voltage, conventionally, a proportional controller (PI) is used to maintain the dc-link voltage at the reference value. The transient response of the PI dc-link voltage controller is slow. So, a fast 
acting dc-link voltage controller based on the energy of a dc-link capacitor is proposed. The transient response of this controller is very fast when compared to that of the conventional dc-link voltage controller. By using fuzzy logic controller instead of the PI controller the transient response is improved. The DC capacitor charging output voltage is increased and the response is fast when compared with fuzzy by using the Neuro -Fuzzy logic controller and hence, the PQ of the system is enhanced.

\section{THE OPERATING PRINCIPLE OF LOAD COMPENSATION DSTATCOM AND SYSTEM CONFIGURATION}

Fig.1 shows a schematic diagram for load compensation using an ideal shunt compensator like a DSTATCOM by inject current ic at the PCC to cancel the reactive and harmonic load current il [2], [7]. Fig.2 shows a configuration of a network where DSTATCOM is used to regulate the voltage on a $1.2 \mathrm{kV}$ distribution power system [14], with a fixed load connected. The DSTATCOM uses Voltage Source Converter (VSC) to regulate voltage at PCC by absorbing or generating reactive power using power electronics to regulate three phase sinusoidal voltage at its terminal. The VSC uses forced-commutated power electronic devices (GTOs, IGBTs or IGCTs) to synthesis the voltage on the secondary side of the coupling transformer from a DC voltage source [14], [15]. A DSTATCOM with VSC using IGBT-based PWM inverters has been used in this study. Fig. 3 depicts a single-line diagram of the DSTATCOM and the control system block diagram of DSTATCOM.

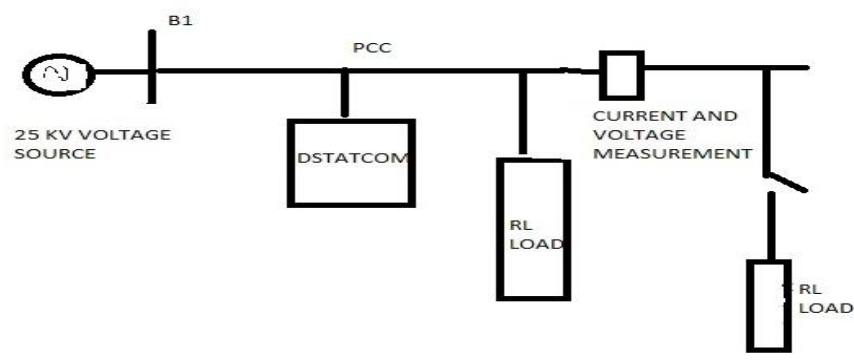

Figure.2. System configuration of a distribution network

In Fig.3, PLL represents the phase-locked loop used to synchronize on the positive sequence component of the three phase $(3 \Phi)$ primary voltage V1. The output of the PLL is $\theta=\omega t$ and it is used to compute the direct-axis and quadrature

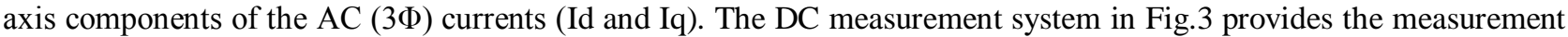
of the DC voltage Vdc. The AC voltage measurement and current measurement systems in Fig. 3 measure the $d$ and $q$ components of AC positive-sequence currents to be controlled.

The DC voltage regulator maintains DC link voltage constant and ac voltage regulator maintains system voltage to be within the permissible limits. Id tells about active power drawn by VSC to maintain DC link voltage constant. Iq tells about the reactive power needed to be generated by VSC for reactive power compensation.

Here hysteresis controller is used to generate pulses for VSC because as Dstatcom is a shunt device it injects current Ic and provides compensation. So, current control of vsc is needed which is done easily by hysteresis controller.

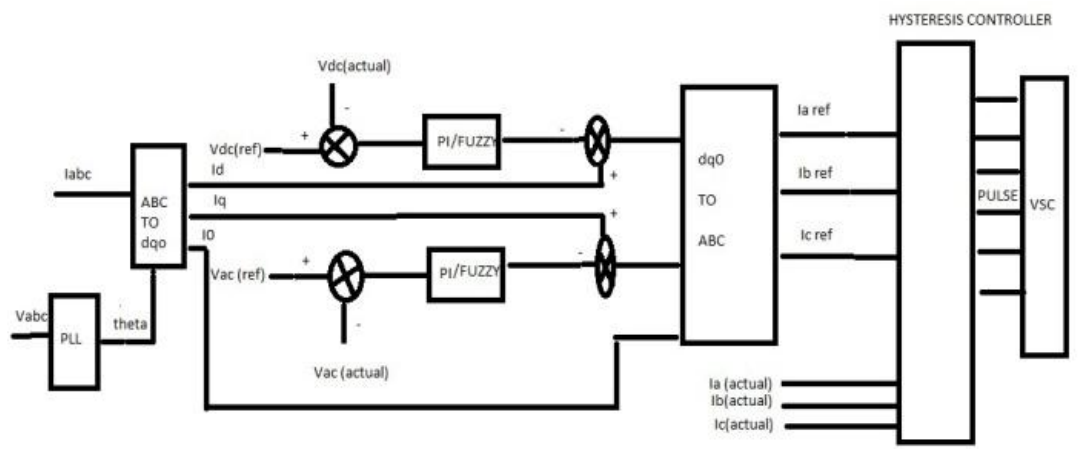

Figure.3. DSTATCOM control system block diagram

(Idref-Id) and (Iqref-Iq) are given to dqo to abc block which generates reference currents for compensation. These reference currents along with actual currents are given to hysteresis controller which generates pulses needed for VSC. 
UGC Approved Journal

\section{HYSTERESIS CURRENT CONTROL SCHEME}

Hysteresis band control technique is most suitable for current controlled voltage source inverter. Current controlled PWM have following advantages:

1. No phase and amplitude errors providing ideal tracking

2. Provide better dynamic response of the system

3. Low harmonic content
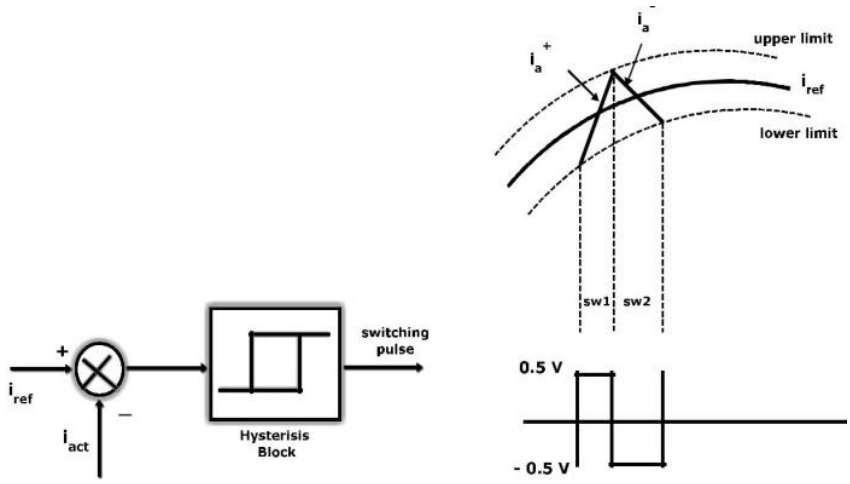

Figure.4. Block diagram of hysteresis band controller

In Fig.4, shows hysteresis controller generates pulses based on reference and actual current. It controls the to be within the band itself.

\section{FUZZY LOGIC CONTROLLER DESIGN FOR THE DSTATCOM}

A fuzzy logic controller (FLC) consists of four elements. These are a fuzzification interface, a rule base, an inference mechanism, and a defuzzification interface [16]. A FLC has to be designed for the DC voltage regulator, AC voltage regulator, and the current regulator. The design of the FLC for DC voltage regulator is described in detail first. The design of the fuzzy controllers for the AC and current regulators follows similar procedure. The PI-like FLC designed for DC voltage regulator has two inputs and one output. The error $(\mathrm{t})(\mathrm{e}=\mathrm{Vdcref}-\mathrm{Vdc})$ and the rate of change of error $\left({ }^{\circ} \mathrm{e}(\mathrm{t})\right.$ )are the inputs and the output of the FLC is $\Delta \mathrm{Id}$. In fact, $\Delta \mathrm{Id}$ is integrated to produce Idref. Fig. 4 shows the block diagram of the DC voltage regulator where GE, GCE, and GCU are the scaling factors for the inputs and output, respectively.

The linguistic variables for error $\mathrm{e}(\mathrm{t})$, the rate of change of error $(\dot{\mathrm{e}}(\mathrm{t}))$ and the controller output $\Delta \mathrm{Id}$ will take on the

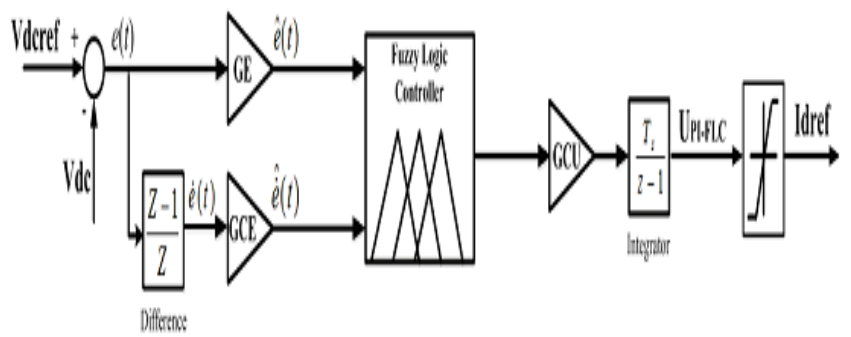

Figure.5. DSTATCOM control system block diagram

Following linguistic values:

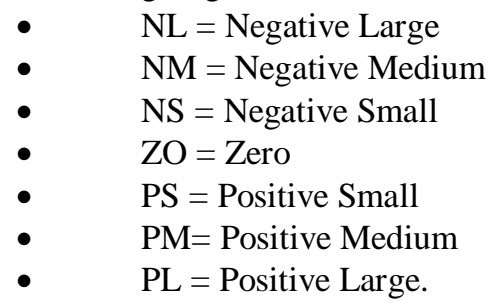

The above linguistic quantification has been used in this paper to specify a set of rules or a rule-base. The rules are formulated from practical experience. For the FLC with two inputs and seven linguistic values for each input, there 


\section{UGC Approved Journal}

Vol. 4, Issue 6, June 2017

are $7^{2}=49$ possible rules with all combination for the inputs. The tabular representation of the FLC rule base (with 49 rules) of the fuzzy control based DC voltage regulator is shown in Table 1.

TABLE $17 \times 7$ FLC RULE-BASE IN TABULAR

\begin{tabular}{|c|c|c|c|c|c|c|c|}
\hline$e_{e(t)} \dot{e}(t)$ & NL & NM & NS & ZO & PS & PM & PL \\
\hline PL & $\mathrm{ZO}$ & PS & PM & PL & PL & PL & PL \\
\hline PM & NS & $\mathrm{ZO}$ & PS & PM & PL & PL & PL \\
\hline PS & $\mathrm{NM}$ & NS & $\mathrm{ZO}$ & PS & PM & PL & PL \\
\hline Z0 & NL & NM & NS & $\mathrm{ZO}$ & PS & PM & PL \\
\hline$\overline{\mathrm{NS}}$ & NL & $\mathrm{NL}$ & NM & NS & $\mathrm{ZO}$ & PS & PM \\
\hline NM & NL & $\mathrm{NL}$ & NL & $\mathrm{NM}$ & NS & $\mathrm{ZO}$ & PS \\
\hline NL & NL & $\mathrm{NL}$ & NL & $\mathrm{NL}$ & $\mathrm{NM}$ & NS & ZO \\
\hline
\end{tabular}

The membership functions to be employed for the inputs are of the triangular type where the membership functions for the output are singletons. The membership functions for the inputs and the output of the fuzzy controller for the DC voltage regulator are shown in Figs. 5, 6, and 7, respectively.

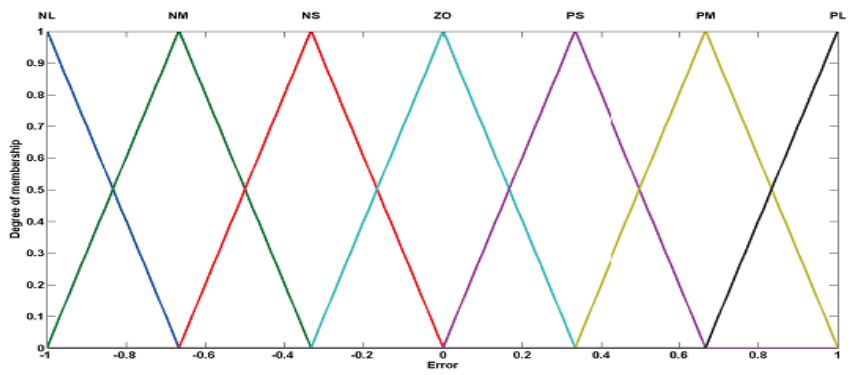

Figure.6. Membership functions of the input error e(t)

Figs. 8 and 9 illustrate the block diagram of the fuzzy controllers as the AC voltage regulator and current regulator

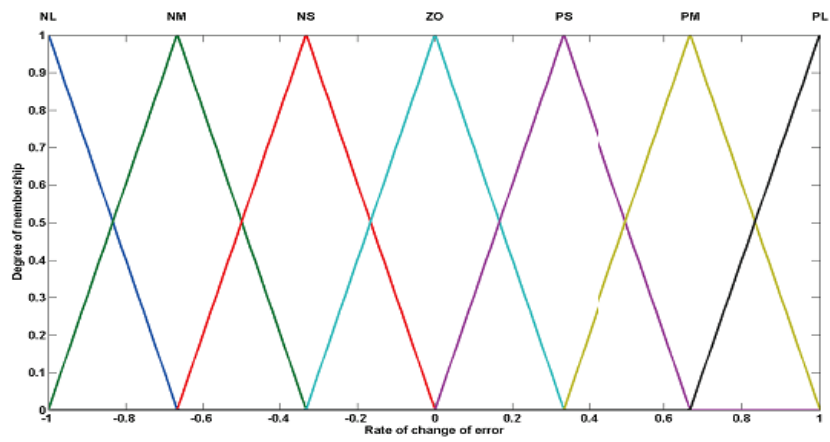

Figure.7. Membership functions of the input the rate of change of error $(\dot{\mathrm{e}}(\mathrm{t}))$

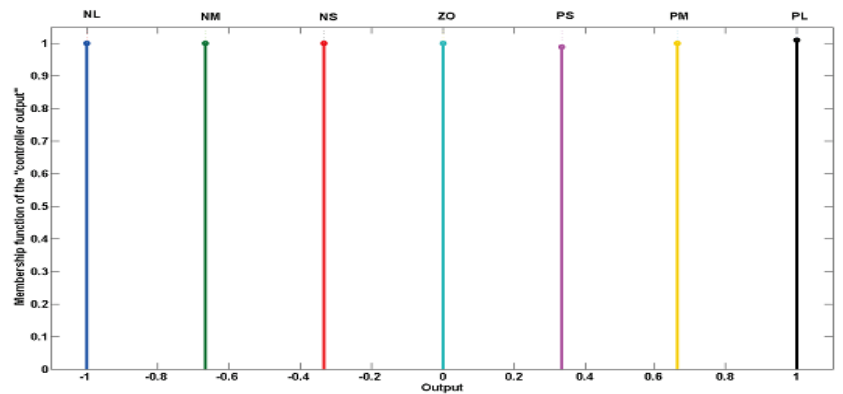

Figure.8. Membership functions of the output of fuzzy logic controller

Which has similar structure of the FLC DC voltage regulator? Again GE, GCE, and GCU are the scaling factors for the inputs and output, respectively. 
UGC Approved Journal

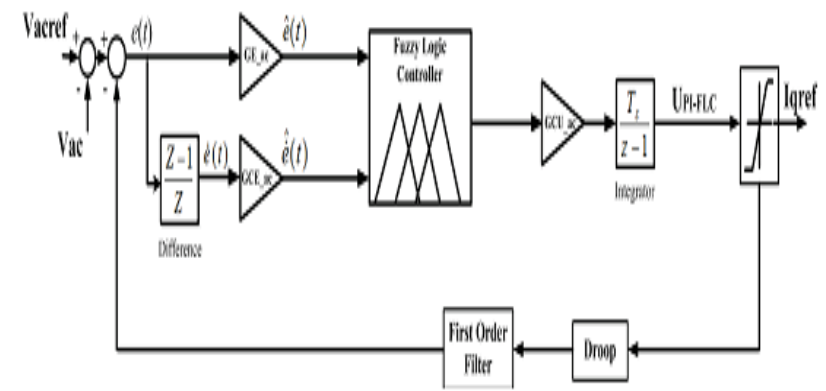

Figure.9. Block diagram of the fuzzy logic based AC voltage regulator

DC voltage regulator maintains constant dc link capacitor voltage of inverter and ac regulator maintains voltage with in permissible limits.

\section{MATLAB/SIMULINK RESULTS}

Fig.10 shows basic simulation diagram designed. Here sudden load switching, source voltage variation and source harmonics are mitigated using DSTATCOM.

A comparison study is made for all above mentioned power quality issues with pi, fuzzy and without DSTATCOM. Fig. 13 shows comparison study for sudden load switching indicates undershoots of $6.5 \mathrm{v}$ for without DSTATCOM, $2.4 \mathrm{v}$ for pi and 1.9v for fuzzy based DSTATCOM. Fig.15 shows comparison study of pi, fuzzy and without DSTATCOM for source variation indicates over shoot of $33 \mathrm{v}$ for without DSTATCOM, $29 \mathrm{v}$ with pi and $23 \mathrm{v}$ for fuzzy controlled DSTATCOM. Fig. 17 shows load current when harmonics are created in system.

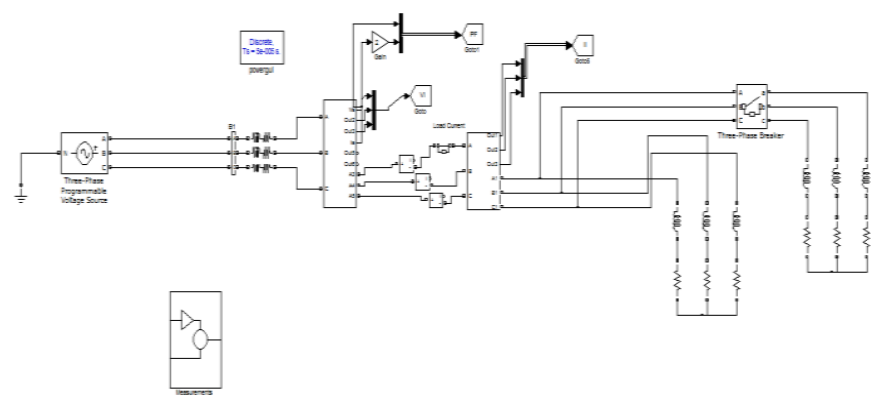

Fig.10 Simulink diagram of sudden load switching without DSTATCOM

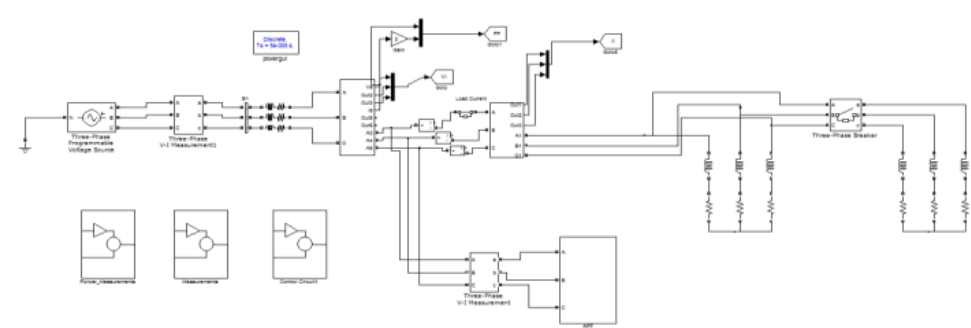

Fig.11 Simulink diagram of sudden load switching PI controlled DSTATCOM

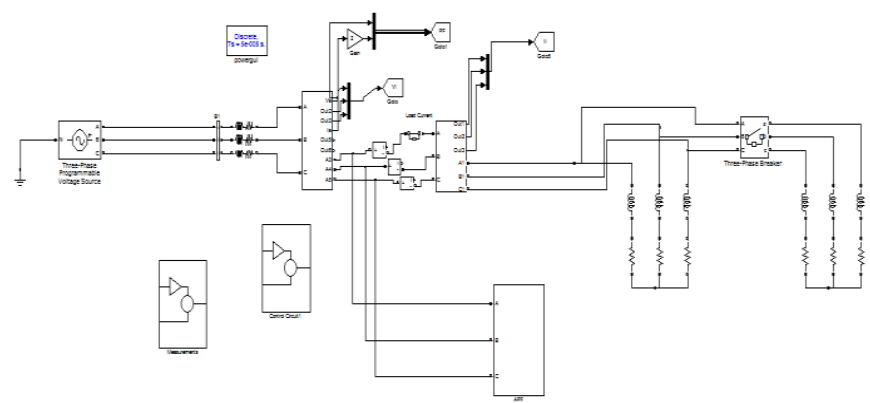

Fig.12 Simulink diagram of sudden load switching fuzzy controlled DSTATCOM 
UGC Approved Journal

IARJSET

ISO 3297:2007 Certified

Vol. 4, Issue 6, June 2017

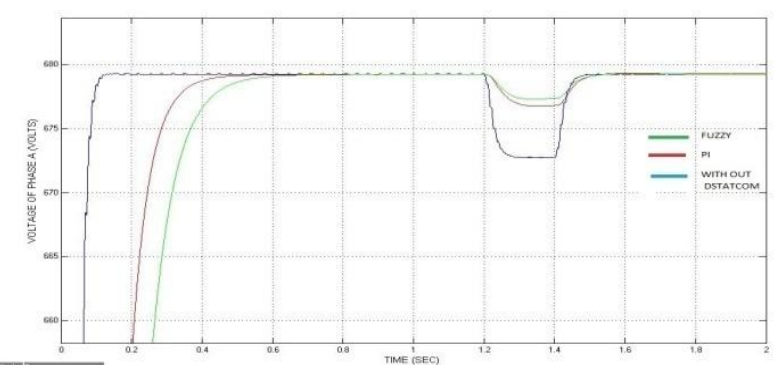

Fig.13 Comparison of sudden load switching with PI, fuzzy controlled DSTATCOM and without DSTATCOM

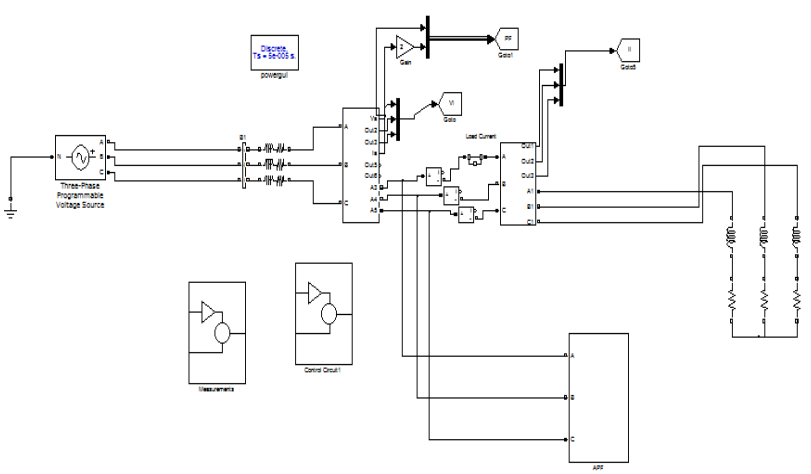

Fig.14 Simulink diagram of voltage sag and swell on source side with DSTATCOM

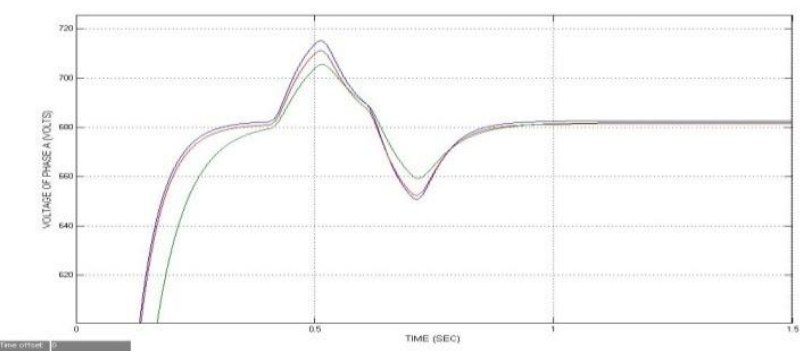

Fig.15 Comparison of voltage swell and sag on source side with PI, fuzzy controlled DSTATCOM and without DSTATCOM

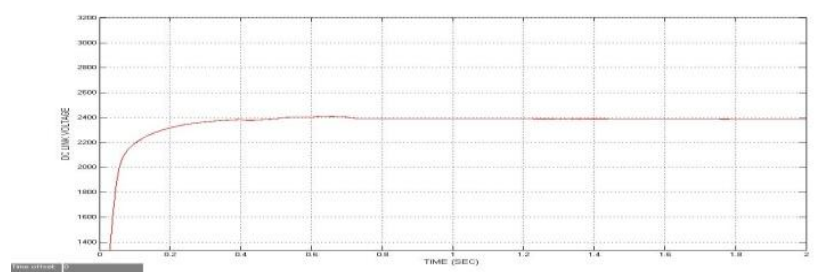

Fig.16 Dc link capacitor voltage

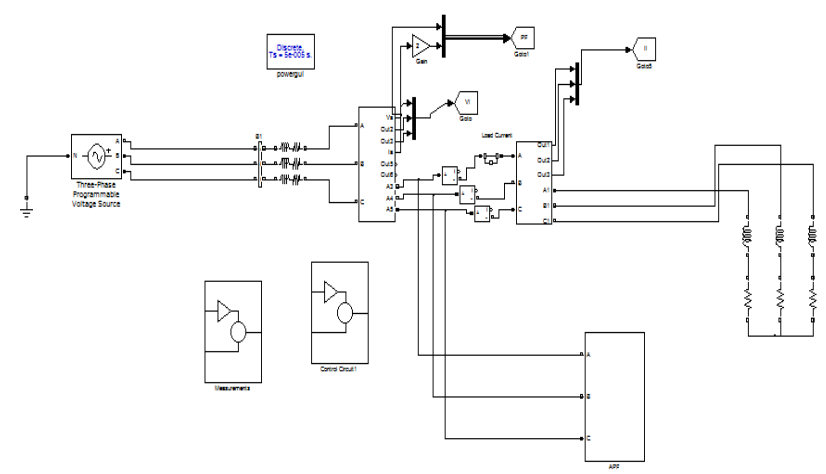

Fig.17 Simulink diagram of harmonics on source side with DSTATCOM 


\section{UGC Approved Journal}

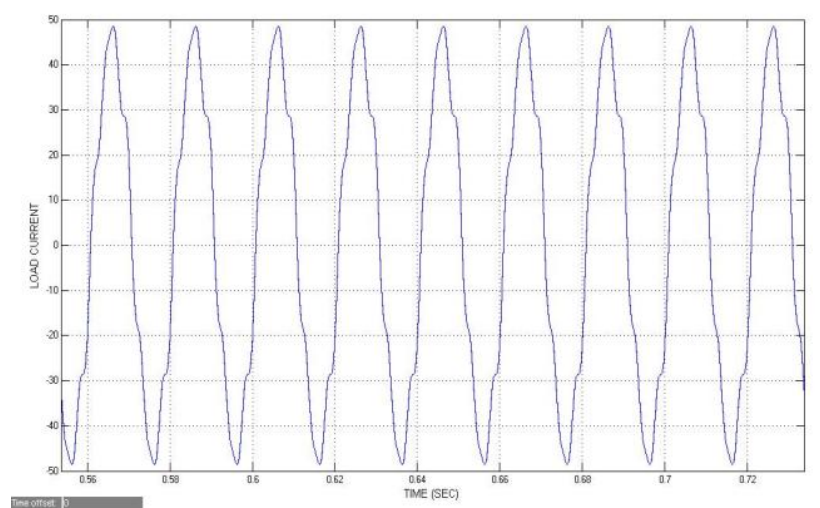

Fig.18 load current without DSTATCOM

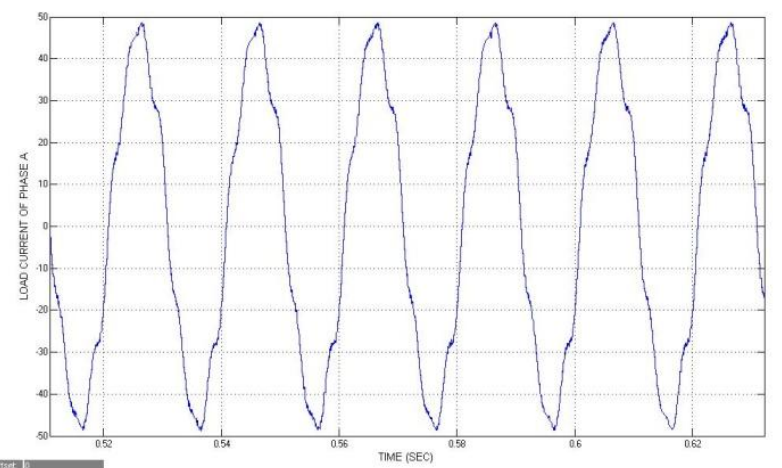

Fig.19 load current with PI controlled DSTATCOM

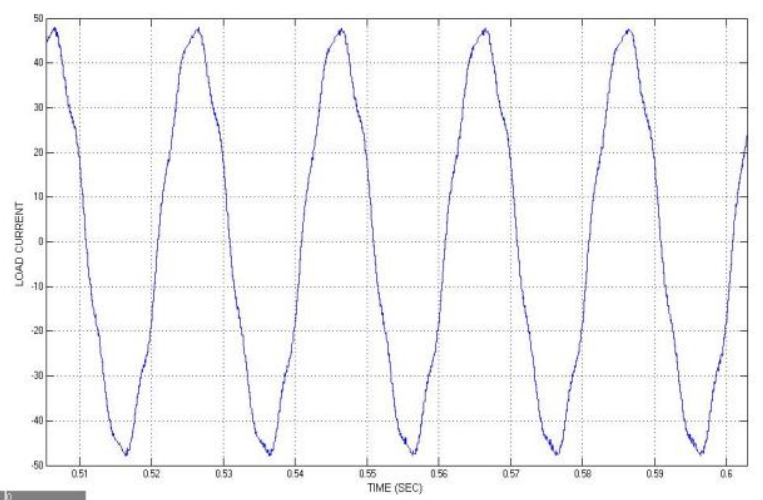

Fig.20 load current with fuzzy controlled DSTATCOM

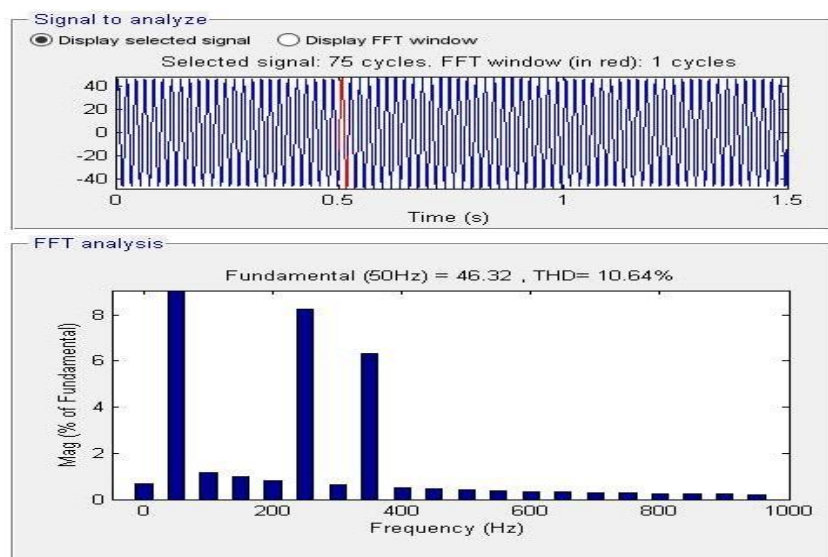

Fig.21 FFT plot of load current without DSTATCOM 
UGC Approved Journal

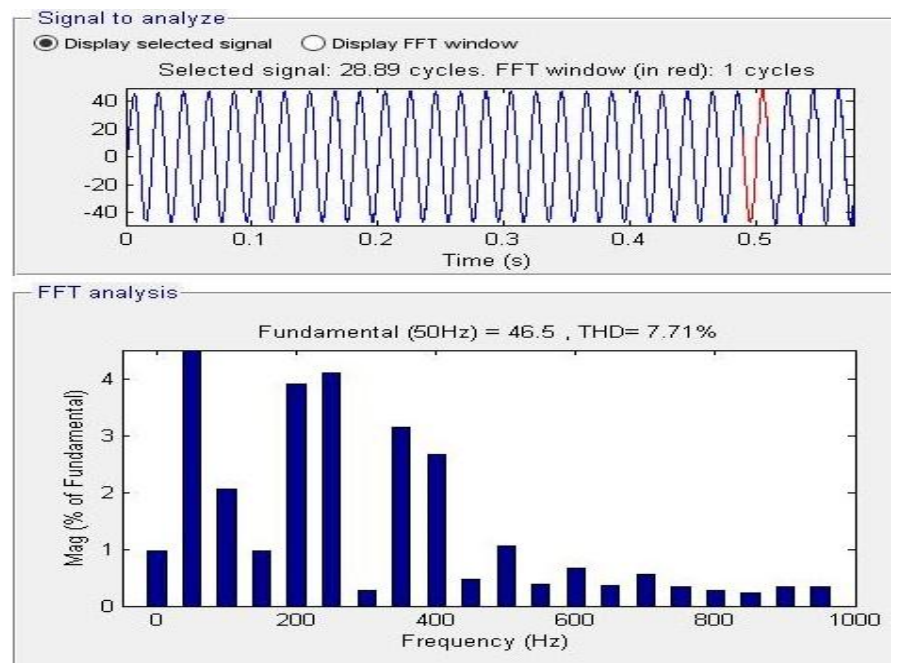

Fig.22 FFT plot of load current without DSTATCOM

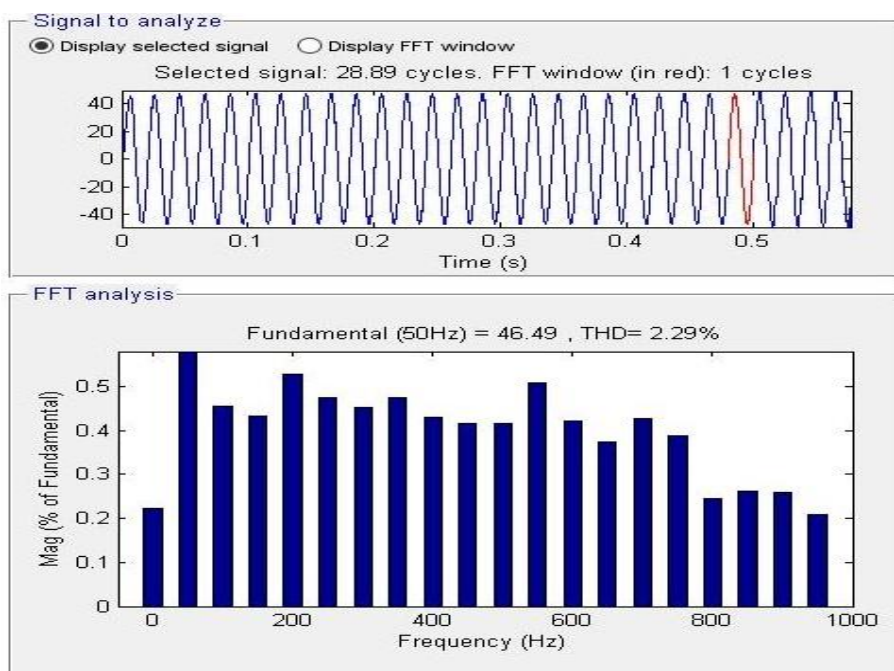

Fig.22 FFT plot of load current without DSTATCOM

TABLE II. SYSTEM PARAMETERS

\begin{tabular}{|l|l|}
\hline System Parameters & Numerical Values \\
\hline Source Voltage & $1200 \mathrm{~V}$ \\
\hline Source Impedance & $0.1+0.282 \mathrm{j}$ \\
\hline Load & $20+6.28 \mathrm{j}$ \\
\hline DC link capacitor & $1500 \mathrm{uF}$ \\
\hline Choke & $0.1+13.18 \mathrm{j}$ \\
\hline Variable load & $0.2+0.564 \mathrm{j}$ \\
\hline Hysteresis controller band & $0.01 \mathrm{~A}$ \\
\hline
\end{tabular}

\section{CONCLUSION}

The paper proposes pi and fuzzy logic controller for a DSTATCOM to improve power quality and dynamic performance of a distribution power system has done. FLC is designed for the DC voltage regulator, AC voltage regulator. The effect of Harmonic compensation using PI and Fuzzy Controller was evaluated. The results were compared with those of a conventional PI controlled DSTATCOM in the presence of source voltage variation and large load variations. The results show that the system's performance was dramatically improved by using FLC. DC link voltage is maintained constant in PI and fuzzy controller. The efficacy of the proposed controller is established through a simulation. It is observed from the above studies the proposed fuzzy logic controller gives the fast transient response for fast varying loads. 
UGC Approved Journal

IARJSET

Vol. 4, Issue 6, June 2017

\section{REFERENCES}

[1] K. Schipman, and F. Delince,” The importance of good power quality,” ABB Power Qual. Prod., Charleroi, Belgium, ABB Review, Apr., 2010.

[2] A. Banerji, S. K. Biswas, and B. Singh, DSTATCOM Control Algorithms: A Review, International Journal of Power Electronics and Drive System (IJPEDS), vol.2, no.3, pp. 285-296, 2012.

[3] G. F. Reed, M. Takeda, F. Ojima, A. P. Sidell, R. E. Chervus, and C.K. Nebecker, Application of a 5MVA, 4.16kV D-STATCOM system for voltage flicker compensation at Seattle iron \& metals, IEEE PES SM,pp. 1605-1611, 2000.

[4] A. Ghosh, and G. Ledwich, Load Compensating DSTATCOM in Weak AC Systems, IEEE Trans. on Power Delivery, vol. 18, no.4, Oct. 2003.

[5] S. Kincic, and A. Chandra, Distribution Level STATCOM (DSTATCOMs) for Load Voltage Support, IEEE Proceedings of Power Engineering Conference on Large Engineering Systems, pp 30-37, 2003.

[6] B. Singh, and J. Solanki, A Comparison of Control Algorithms for DSTATCOM, IEEE TRANSACTIONS ON INDUSTRIAL ELECTRONICS, vol. 56, no. 7, pp. 2738-2745, 2009.

[7] K. K. Kora, A Fuzzy logic DC-Link Voltage Controller for Three-Phase DSTATCOM to Compensate AC and DC Loads, International Journal of Scientific \& Engineering Research, vol. 2, no. 10, pp. 1-13, 2011.

[8] D. Prasad, T. S. Kumar, B.V. Prasanth, and K. S. G. Sankar, Fuzzy Logic Control of DSTATCOM for Power Quality Improvement, Int. Journal of Engineering Research and Applications, ISSN : 2248-9622, vol. 3, no.6, pp.398-403, 2013.

[9] J. Shi, A. Kalam, and P. Shi, Improving Power Quality and Stability of Wind Energy Conversion System with Fuzzy Controlled STATCOM, Australian Journal of Electrical and Electronic Engineering, 2014.

[10] A. Noshadi, J. Shi, W. S. Lee, and A. Kalam, PID-type Fuzzy Logic Controller for Active Magnetic Bearing System, IEEE Proceedings of40th Annual Conference of IEEE Industrial Electronics, pp. 241-247,2014.

[11] A. Noshadi, J. Shi, S. Poolton, W. S. Lee, and A. Kalam, Comprehensive experimental study on the stabilization of active magnetic bearing system, IEEE Proceedings of Australasian Universities Power Engineering Conference, pp. 1-7, 2014

[12] A. Noshadi, J. Shi, W. S. Lee, P. Shi, and A. Kalam, Optimal PID type Fuzzy Logic Controller for a Multi-Input Multi-Output Active Magnetic Bearing System, Neural Computing and Applications, DOI: 10. 1007/s00521-015-1996-7, 2015.

[13] A. Noshadi, M. Mailah, and A. Zolfagharian, Intelligent active force control of a 3-RRR parallel manipulator incorporating fuzzy resolved acceleration control, Applied Mathematical Modelling, vol. 36, no. 6,pp. 2370-2383, 2012.

[14] The MathWorks, SimPowerSystems Users Guide, MatlabR2013b.

[15] N. G. Hingorani, and L. Gyugyi, Understanding FACTS; Concepts and Technology of Flexible AC Transmission Systems, IEEE Press book, 2000 . 